\title{
Research on the Construction of "Internet + Government Services" Platform in Chinese Cities Based on Big Data: Subject Dilemma and Optimization Path
}

\author{
Shaogang Liao, Wendong Xie, Songdan Yi \\ School of Public Finance and Public Administration, Jiangxi University of Finance and Economics, Nanchang, China \\ Email address: \\ liaoshaogang@163.com (Shaogang Liao) \\ To cite this article: \\ Shaogang Liao, Wendong Xie, Songdan Yi. Research on the Construction of "Internet + Government Services" Platform in Chinese Cities \\ Based on Big Data: Subject Dilemma and Optimization Path. International Journal of Economic Behavior and Organization. \\ Vol. 6, No. 2, 2018, pp. 38-44. doi: 10.11648/j.ijebo.20180602.12
}

Received: May 16, 2018; Accepted: June 8, 2018; Published: July 7, 2018

\begin{abstract}
Relying on big data to build an "Internet + government service" platform is an important task in building a service-oriented government, and it is a good way to improve government service capabilities. The rapid development of network information technology has brought certain challenges and opportunities for the development of China's social economy and government governance. This paper mainly studies the construction of the "Internet + government service" platform in Chinese cities under the background of big data. Taking Nanchang City for example, the author did deep analysis on the difficulties faced by the construction of "Internet + government services" in Chinese cities, and learned from Guiyang's innovative development and achievements by using big data, then proposed the promotion of "Internet + government services" in Nanchang City.
\end{abstract}

Keywords: Internet+, Government Services, Big Data, Platform Construction

\section{Introduction}

As the State Council of China issued the "Guidance Opinions on Accelerating the Implementation of "Internet + Government Services ([2016] No.55)" in 2016, and related work were promoted and implemented. The development of government services in China is further integrated with the development of the Internet. Governments and departments at all levels have established government service platforms based on the "Internet+" to implement "Opinions" implementation plan. But nationwide, the construction of government service platforms is uneven, many places focus on "+ Internet" rather "Internet + " especially in underdeveloped regions. These areas combined Internet and government services mechanically without service quality and high level of service. As a result, there is no real benefit to the people and enterprises. Under the background of rapid development of big data, great changes have taken place in government governance concepts and methods. Especially the change on Internet + government services, which has made government services and information more people-friendly and intelligent [1]. Governments should change their development concepts and innovate platform service models, build a "Internet + government services" new model driven by big data. As a second-tier city in China, Nanchang starts late in the construction of government service platforms, with single model and many development problems. Guiyang City, which is a second-tier city too, has made the Guiyang Municipal Affairs Service a success and has become a leader in the country with advanced big data development. Guiyang city has become a model of service platforms development in underdeveloped regions. Therefore, drawing lessons from the development experience of Guiyang City can help to quickly improve the construction of the "Internet + government service" platform driven by big data in Nanchang, and provide reference experience for the construction of other city service platforms, and finally promote the national "Internet+ government services" progress together. 


\section{2. "Internet + Government Services": The Transformation of Local Government Governance in the New Era in China}

In the information age, people's life needs have become increasingly personalized and diversified, and the demand for public services has also increased. The demands of the public have placed higher demands on the government both in terms of form and content. The offline service of government has been unable to meet the growing demand of the public. The government service capacity of the offline has lagged behind, service efficiency is low, and public services supply and demand are seriously unbalanced. Moreover, the low awareness of public administrative staff and offline administrative affairs need to take a long time to wait in line, which wastes a great deal of the public's time cost and energy, resulting in widespread dissatisfaction with the government's services and even disputes with administrative staff. This has led to increased conflicts between the people and the government. "Internet + government services" is the government's compliance with the requirements of the "Internet + " era. The reforms and innovations in government governance are the only way for the reform of China's administrative management system in the new era [2]. Driven by current big data, "Internet + government services" as an innovative model whose application effect is significant, which promotes the standardization of the approval, service and supervision work, and provides the masses more high-quality and efficient services [1].

Without informatization there will be no modernization of government services. With the rapid development of global informatization, networking, science and technology, the government management and public service models have also undergone tremendous changes. As a result, there is a wave growing up about the transformation of government functions and the construction of a seamless service model [3]. The introduction of Internet technology provides a new way of thinking for the government service. With the aid of big data, cloud computing and other information technology means, government affairs service can beyond time and geographical constraints, make reconstructing the government service mode, and improve the government administrative service breadth and depth. "Internet + government affairs" as a new type of governance is playing an increasingly important role in promoting the modernization of government governance [4]. Integrating the "Internet + " thinking into government affairs services has created a new public service bridge between the government and society, enabling the government to gather and integrate more effective information, providing the community with a comprehensive, efficient, convenient, and transparent public services, reducing government service costs and the cost handling the people's affairs. "Internet+ government service" is a new opportunity for the improvement of government management service awareness, promotes the change of government governance service concept from the manager to the supervisor and service provider [5]. At the same time, Internet + also created a new era of government services, providing good opportunities and technical conditions for the new model of innovative government services [6].

\section{The Dilemma of the Construction of "Internet + Government Services" Platform in Chinese Cities-Taking Nanchang as an Example}

At present, Chinese cities have many problems in advancing the construction of the "Internet + government services" platform. Take Nanchang City as an example, the implementation of the government service platform for the convenience of "Internet + government services" by the Nanchang municipal government is still in start-up stage. The level of government informatization needs to be improved and the development convenience policies needs to be adjusted. There are still many difficulties in the rapid development process. Specifically, there are the following points:

\subsection{Long E-approval Period and Low Work Efficiency, the Networked Service Needs to Be Further Optimized}

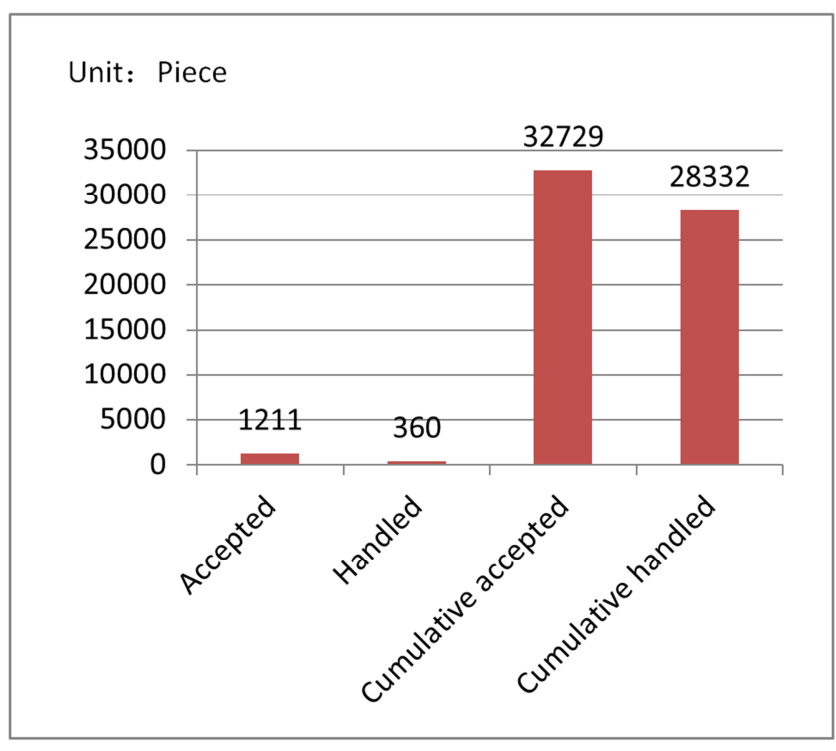

Figure 1. Nanchang Government Service netowrk Approval Data in April.

The approval efficiency of online service is one of the important indicators of government service standards. According to the administrative approval data of Nanchang Municipal Service Network in April 2018 (as shown in Figure 1): In the same month, 1211 cases were accepted, and 360 cases were handled. The total number of receiving events is 32,729 , and 28,332 cases have been completed. From the data, it can be known that less than one third cases can be completed in a month. and the processing cycle of more than 4000 cases over a month have not been finished. Thus, it can be seen Nanchang government services online for approval cycle has low efficiency. In addition, according to the questionnaire survey, most of the approval items must be approved by 
stamping offline, and then uploading to the Internet, which greatly lengthens the approval cycle and reduces the approval efficiency. Although some of the examination and approval items can be handled all by network, but the Internet has only played a role in publicizing the results. People still need to confirm the signing offline. The effect of online service platform convenience still needs further consideration, and the network services need to be further improved.

\subsection{Poor Quality of Service Platform Website and Low Informatization Level}

Without independent government service website, Nanchang municipal government affiliated in Jiangxi government affairs service website, and now it is under a state of commissioning. On the whole, the site coverage is comprehensive. The service items provided by the columns and sub-projects of various levels are similar to the developed provinces and cities, but there is a large gap in the ease of use and effectiveness of the website. Through a questionnaire survey (as show in Figure 2), $42.3 \%$ of the people believe that the government service website is not practical, $23.5 \%$ of the people think that the online service process is very complicated, and $30.2 \%$ of the people think that the service capacity of the website is low. In the construction of the website, there is a tendency of the Internet for Inter. Such as "emphasizing electronics, ignoring government affairs"," emphasizing technology, and ignoring services", blindly pursuing the construction of the site and the client, taking great efforts in terms of form. However, the government ignored the use of "Internet + " to raise awareness of service levels [7]. In terms of the informatization of the government service platform, there are problems such as the low level of information and the inconsistent links between the various departments. First of all, this kind of problem arises because the website's operation and management mechanism is not perfect, and each department cannot fully coordinate in the process of providing informatization services; secondly, departments pay less attention to the platform's operation and management, resulting in website crashes in a long time and failed to access and recover in time. Thirdly, the constructers of the platform failed to keep up with the times. In the rapid development of the Internet, they failed to use modern technologies to achieve website upgrades and service upgrades.

\subsection{Lacking Promotion About Online Government}

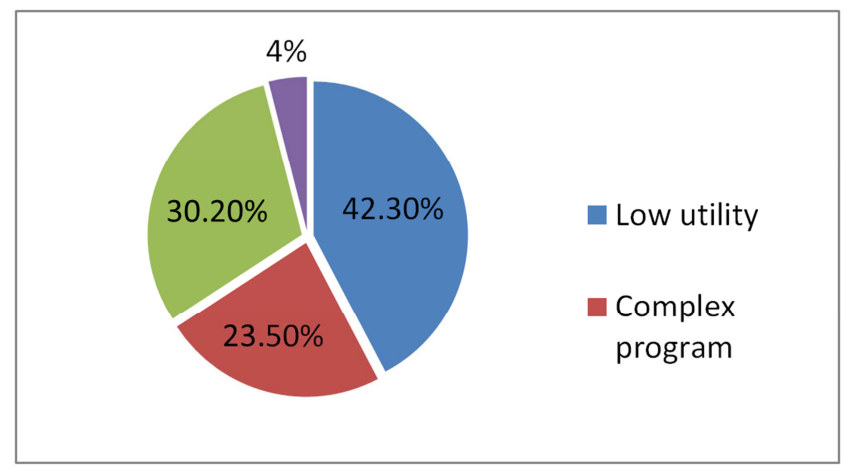

Figure 2. The use of government service network in Nanchang.

\section{Service Platform, Low Popularizing Rate}

In the construction of the "Internet + government service" platform, more emphasis was placed on the construction of the platform rather the promotion of online service platforms, lacking popularization of the use of online platforms. Secondly, how to guide the enterprises and the public to deal with affairs on the net and is lacking promotion. So that the masses do not understand the service platform and distrust online service. As a result, the public prefers to spending much time offline rather than deal with affairs online. On the other hand, there are few services that can be directly handled on the government's government affairs website. Many projects are not included in "Internet + government services" system. Although some projects are included formally, in fact there are no related services on the website. According to the survey results of Nanchang relevant groups questionnaires (as show in Figure 3), 70.2\% of the people said that they have never used the government service website, and only $28.3 \%$ of the surveyed people had used the online service platform when dealing related affairs. Therefore, the online service platform promotion should be improved further.

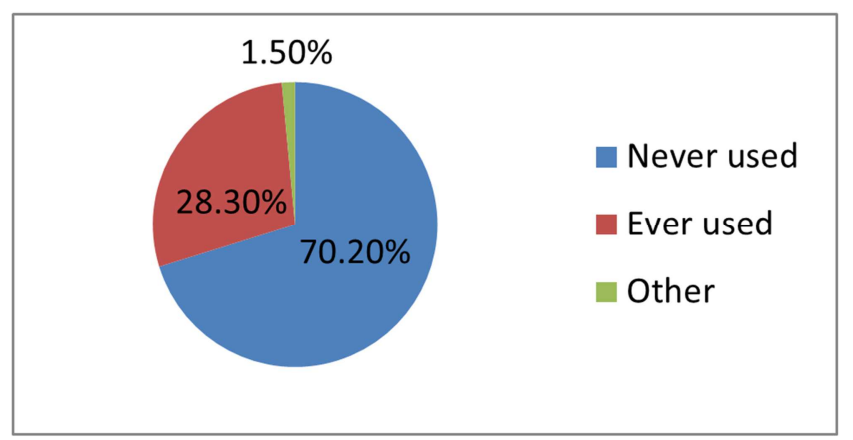

Figure 3. Public Use of Nanchang Municipal Service Network.

\subsection{Information Disclosure Is Delayed and the Disclosure Is Not Enough, Information Sharing Is Low}

Modern society is an information society with strong effectiveness. The timely disclosure of information can effectively protect citizens' right of information and stimulate the vitality of information resources, greatly improve the use of information. According to information published on the Nanchang Municipal Service Network, most of the information and data are months or even a year ago. Most of the published information and data are secondary information and lack information that the public really cares about. According to the statistics on the website from February 2016 to February 2018 (as show in Figure 4), the information published is mainly the executive meeting, related documents, laws and regulations. However, the use of funds, such as the use of infrastructure funds, "Three Publics" funds, confiscated income, and other government information disclosure is not clear [8]. In addition, the information between government departments is encapsulated and data protection is serious. There is no government information and data sharing mechanism. Low degree information sharing makes the phenomenon of "information islands". Each department's 
information is owned by each department and is not shared. The information database is used by other departments to build an "Internet + government services" platform that urgently needs to break barriers to data sharing.

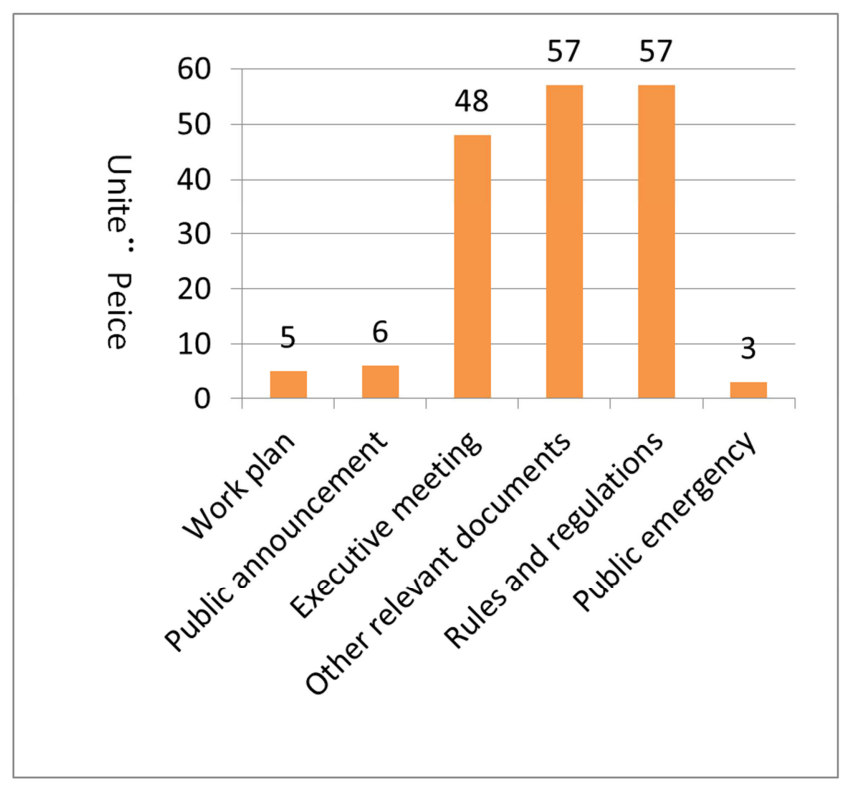

Figure 4. Information Release of Nanchang City in 2016.2-2018.2.

\section{Big Data Drives Government Services: Construction of "Internet + Government Service" Platform in Guiyang, China}

Although Guiyang City is a second-tier city in China like Nanchang. In recent years, for deeply committed to implementing the relevant decision-making arrangements concerning innovation-driven development of the Party Central Committee, State Council, and Guizhou Provincial Party Committee, Guiyang government actively explores the road of economic development and ecological protection in less-developed regions, and the development of big data industry has been rapid developed. At the same time, the "big data" of the government service center of Guiyang has stepped into the forefront of the whole country and formed the guiyang model of "Internet + government service". On October 26, 2015, Guizhou Province issued the Opinions "on Further Strengthening the Construction of Public Service Platforms" which further promoted the development of "Internet + government services" in Guiyang. Guiyang City's experience in using big data to promote "Internet + government services" has important practical significance for the construction of Nanchang's municipal service platform.

\subsection{The Main Approach of Building an "Internet + Government Service" Platform in Guiyang City}

(1) Build a "Big Data Livelihood" Project Integrated Service Platform of "One Net", "One Number" and "One Window"

The "Big Data Livelihood" project (abbreviated as "BDL") is one of the "ten key projects for creating innovative center cities led by big data", put forward by the Sixth Plenary Session of the Guiyang Municipal Party Committee and based on big data development and application of "Internet + people's livelihood services"[9]. It is based on the application of big data open applications and honest services, using the Internet as a means, taking the people's livelihood service index as the standard, and integrating innovation as the specific method. The way of project operating is based on "government-led, diversified co-construction, government-enterprise joint ventures". Based on the "big data and people's livelihood" engineering integrated service platform as the basic carrier, it will speed up government services through data sharing and service collaboration of "horizontal integration, vertical integration, and online and offline integration." The project implements the " $1+\mathrm{N} "$ technology framework to realize the collection of people's livelihood data on the platform. The performance evaluation of the people's livelihood service is reflected on the platform. According to the work methods of informatization, dataization, self-discipline, and integration, the public through "one net" one number" and "one window" for convenient livelihood services. (as show in Table 1)

Table 1. One Net, One Number and one Window.

\begin{tabular}{|c|c|c|}
\hline One Net & One Number & One Window \\
\hline $\begin{array}{l}\text { Relying on the "Cloud Guizhou-Guiyang Platform", } \\
\text { the data generated by the free WIFI network in } \\
\text { Guiyang City, the government affairs data in the } \\
\text { government office system, the service data of the } \\
\text { public service industry, and various business data are } \\
\text { integrated into the the platform [9]. The } \\
\text { communication resources, computing resources, } \\
\text { storage resources, and system resources are } \\
\text { aggregated into a "one network" to provide physical } \\
\text { infrastructure support for the integrated platform. }\end{array}$ & $\begin{array}{l}\text { Around the "one number" to collect data and use } \\
\text { data, to open up all services in the field of people's } \\
\text { livelihood services. Demand-oriented through the } \\
\text { data open workshop, the data is precipitated, } \\
\text { correlated, and aggregated in a physically } \\
\text { decentralized and logically interconnected manner } \\
\text { to achieve data collection and excavation; the data is } \\
\text { cleaned, processed, and assembled as required by } \\
\text { the open plant in the data field and provides the } \\
\text { available data for the required standard. }\end{array}$ & $\begin{array}{l}\text { Integrate online service channels and } \\
\text { integrate big data livelihood projects into } \\
\text { existing offline service channels. Through } \\
\text { the coordination of online and offline } \\
\text { channels, it can be true that "one-window } \\
\text { acceptance and one-stop service" and } \\
\text { integrate online and offline management to } \\
\text { achieve the same city-wide management } \\
\text { and close-to-registration [9]. }\end{array}$ \\
\hline
\end{tabular}

(2) Grasping Open Sharing of Data and Building a Government Data Sharing Platform

In March 2017, Guiyang City promulgated and implemented the "Guiyang Municipal Government Data Sharing and Opening Regulations" and issued the "Guiyang Municipal People's Government's Implementation Opinions 
on Accelerating the Opening and Sharing of Government Data". Taking the "one network, one directory, one enterprise and five platforms" as the carrier, that construct an all-dimensional and three-dimensional open government data sharing management system. Implementing government data sharing to open up the " $50+100 "$ project, exploring the formation of inclusive open and contracted data open and complementary formats, and opening up government data to lead the opening of corporate and social data. The Guiyang Municipal Government Data Sharing Platform has established a government data open platform in accordance with the "Five One" structure. It has pioneered five data classifications of "domains, industries, themes, departments, and services" in China. Greatly improves the convenience and accuracy of data retrieval, positioning, and discovery. It provides innovative data services such as "XLS, JSON, XML, CSV" and other quarterly formats, visual data map display, and "data catalog + service catalog", achieving deep correlation of data open. From January 18, 2017 to mid-May, the platform has opened 51 departments with 1139 data sets, 116 APIs, and 4.97 million pieces of data. At the same time, Guiyang government data opened their WeChat official account to promote multi-channel government data.

\subsection{The Achievements of Guiyang's Construction of an "Internet + Government Services" Platform}

(1) Promoting the Integration of Information Resources and Improving Government Management and Service Level

On the one hand, the online project platform has become a powerful starting point for integrating Guiyang citizen's health service resources and improving industry management efficiency. On the other hand, the construction of an online project platform has achieved information services such as the disclosure of government affairs information, the publicity of administrative licenses, and the convenience of public interest announcements. It has increased the transparency of government work and gradually expanded the transparency and breadth of government affairs, promoting the administration of the government by law. At the same time, it broke the barriers of information sharing among various departments and raised the government's service level and service scope in the social and economic activities of the people and enterprises.

(2) Achieving Information Sharing between Different Domains, Providing Scientific Basis for Accurate Decision-making

Guiyang City has built a comprehensive platform for "big data of people's livelihood" in the city, integrating business data of various industries in various fields, which realized high sharing and exchange of people's livelihood information resources across regions, departments and industries, and promoting the extensive use and depth of information resources. It has improved the level of macroeconomic decision-making and emergency response in the industry, provided decision-making data for the implementation of relevant government policies for major areas of livelihood, and created a comprehensive, standard, and open information resource sharing system for the 13th Five-Year Informationization.

(3) Strengthen People's Livelihood Service Capabilities and Increase Public Satisfaction with the Government

In response to the people's livelihood service problem, the related department will integrate all citizens' service resources and use the big data thinking model of co-construction, sharing, and co-creation to enable citizens to obtain personalization, quality, and convenience public service through "one net", "one number", and "one window". According to 2018 statistics in March (as show in Figure 5), government affairs service center of Guiyang dealt with 7601 events, settlement (including the previous month carry-over) was 7605,7555 were completed in advance, the completion rate was $99.34 \%$ in advance, and the satisfaction of the people was $100 \%$. Through the analysis of big data to guide the quality of people's livelihood services, the supply and demand of the people's livelihood service can be accurately matched; the resource allocation is reasonable; and the management is orderly and efficient. Finally, the people's livelihood big data can become open and shared; and more big data applications and functions are developed to form the people's livelihood service. The sustainable development of the ecological system has been formed and the innovative development of the public health services in Guiyang has been promoted, and public satisfaction with the government has been improved.

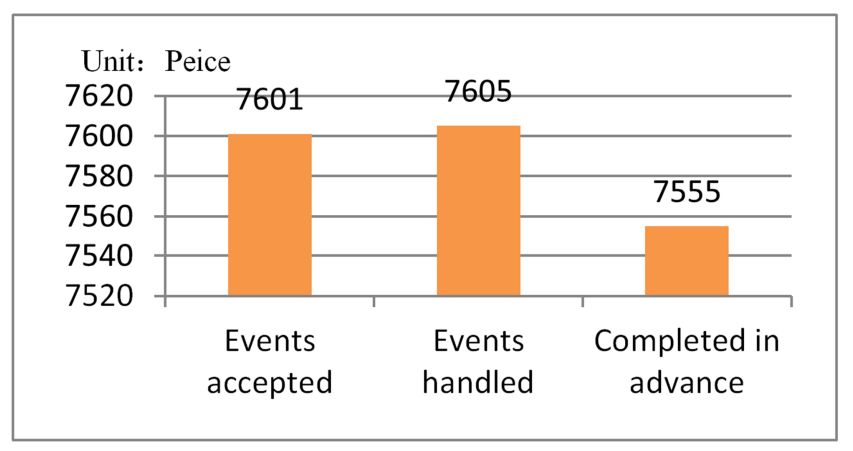

Figure 5. Guiyang City's Administration Services Data in March.

\section{The Optimized Paths for the Construction of "Internet + Government Services" Platform in Chinese Cities}

Under the background of rapid development of big data, the combination of Internet+ thinking to build a government service platform is a new engine to promote innovation in government service models. Based on the current situation of the Nanchang municipal service platform construction and the existing difficulties, combined with the experience and achievements of Guiyang municipal service development, the following points are proposed for the development of the "Internet + government service" platform in Nanchang from the perspective of big data: 


\subsection{Strengthening the Application of Big Data and Increasing the Intensity of Data Exchange and Sharing}

At present, the biggest bottleneck in the construction and development of the Nanchang municipal service delivery platform is the lack of collaborative application sharing systems among various departments, resulting in an "information isolated island" effect in the application of information resources and so on, which is not good for the application development of the e-government platform. In this regard, the local government should draw on the success of Guiyang and rely on big data technology to integrate and aggregate information data of various departments, industries, and fields. Through the establishment of a big data center, data sharing and construction among departments and integrate distributed government service resources can be acheived. A big data platform covering all government departments has been established. All government systems have been relocated to this platform to break through the data barriers between departments and to break the "information isolated island"[9].

\subsection{Optimizing the Service Progress; Achieving "One Application, One Window Handling, One Network Service"}

In order to effectively implement the State Council and provincial government's requirements for "simplify administration and decentralize power, integrate management and optimize public services," and accelerating the construction of "Internet + government services", government must conduct a comprehensive review of online government services. The related department need to make clear instructions on the procedures, methods, and tools and accelerate the process of government government service network. All events that can be handled online must be handled online; No requirements can be put up that the masses submit duplicates materials which can be shared through the Internet; Information that can be verified through the network must not be required to be provided repeatedly by other departments [13]. "One application, one window handling, one network service" can be gradually implemented. Simplify the service process, improve the efficiency of online services, shorten the administrative processing cycle, all kinds of matters can be handled online, and reduce processes, saving time, lower costs. Finally, these can enhance the sense of acquisition of the people and enterprises.

\subsection{Enhancing Publicity and Guidance, Promoting the Public to Actively Participate in "Computer Network"}

Government service platform construction is far from perfect with Single-mode. It needs to rely on mass media, online announcements, and offline promotion to spread channels. Promotion of online government service platform can inform people and enterprises that they can handle affairs and events on the network. They can actively participate in online matters to meet their own service needs. Through multi-faceted propaganda, it is conducive to creating a "computer network" atmosphere for the masses and enterprises, raising awareness and recognition of "one number, one window, one network" [7]. Guiding the public and enterprises to improve the awareness of "computer network" can make people actively participate it and so that the people can save more energy and time to develop a " computer network " habits.

\section{Conclusion}

In the new era, the rapid development and application of big data has provided new development ideas for the "Internet+ government services" of the Chinese government. Governments at all levels should take this opportunity to continuously innovate the management mode of big data "Internet + government services"; continuously improve the level and efficiency of government government services and build a service-oriented government. However, it is a long-term and arduous project to promote the construction of the "Internet + government service" platform. It is difficult to carry out the tasks and implement the work. Governments and departments must keep up with the times, grasp the opportunities in the era of big data development, and constantly improve the construction of government service platforms to improve government services and service levels.

\section{References}

[1] Wang Yu. Big Data Drives the Innovation of "Internet + Government Services" Model [J]. Wisdom, 2017 (03).

[2] Yan Jian, Li Rui, Liu Sana. Opportunities, Challenges and Prospects: "Innovation in Government Governance under the Background of Internet $+"[\mathrm{~J}]$. Journal of Chongqing University of Technology: Social Science, 2017, (1).

[3] Wu Yan. Research on "Internet + Government Service" from the Perspective of Seamless Government Theory----A Case Study on Jiangxi Province [J]. Reform and Opening, 2018 (05):29-31.

[4] Wang Hui. The Problem and Countermeasures of "Internet + Government Services" in Promoting the Modernization of Government Governance [J]. Administration and Laws, 2018 (02): 27-34.

[5] Liu Tao. Research on Government Governance Innovation of "Internet + Government Services" [J]. Cooperation Economy and Technology, 2018 (04):180-183.

[6] Guo Yue, Wang Xiaoshan. An Analysis of the Way to Promote the Development of "Internet + Government Services" in China [J], Southern Agricultural Machinery, 2017, 48 (14):108.

[7] Gao Xuedong, Li Kunxuan. Research on Promoting "Internet + Government Service" Countermeasures: Based on the Third Party Evaluation of "Government Services" Reform of Some Government Departments in Shandong Province [J]. East China Economic Management, 2016, 30 (12): 178-184.

[8] Chen Tan, Deng Wei. Big Data Drives the Innovation of "Internet + Government Services" Model [J]. China Administration, 2016 (7): 7-8. [2]. 
[9] Guiyang " $1+\mathrm{N}$ ” Big Data Livelihood Project Enters Construction Period [J]. Leadership Decision Information, 2016, 36, 12-13.

[10] Wang Duo, Zhou Meijuan. Analyze How to Speed up the Development of the "Internet + Government Service" Platform in Hebei Province [J]. Statistics and Management, 2017, 02, $120-121$.

[11] Zhen Xiaoqiu. Analysis and Research on E-government Platform Construction [J]. Computer Engineering Application Technology, 2015 (1):32-33.

[12] Fan Jiuhong, Chen Wanling. Internet+ Government: Promote the Transformation of Local Government to Service-oriented government [J]. World Telecom, 2015, 05, 47-51.

[13] Li Keqiang Presides over the Executive Meeting of the State Council $(2016$

09 , http://www.gov.cn/xinwen/201609/14/content 5108441.htm.

[14] Du Baogui, Men Lixiang. Advancing Eight Kinds of Relationships in Promoting "Internet + government services"[J]. China Administration, 2016 (7).

[15] Wu Feng, Zhang Yinqiang. Problems and Suggestions in the Construction of Government Affairs Big Data [J]. Social Governance, 2017 (7):49-52.

[16] Xu Shuangming. Accelerate the Promotion of "Internet + Government Services" [J]. Policy, 2017 (6):20-21.

[17] Tang Sheng. Grab the Commanding Heights of the Big Data Credit Standards [N]. Guiyang Daily, 2015-05-28 (B06).

[18] Wang Yong, Hu Guangwei. E-government services under the service oriented logic -- conceptual models, key elements and characteristics analysis $[\mathrm{J}]$. modern intelligence, 2018, 38 (05): $17-24$.

[19] Murathan Kurfal1, Ali Arifoğlu, Gül Tokdemir, Yudum Paçin. Adoption of e-government services in Turkey [J]. Computers in Human Behavior, 2017, 66.

[20] Sun Zhiqiang of Jiangsu province "Internet plus government service system construction research of [J]. Tianjin science and technology, 2018, 45 (04): 1-4.

[21] Li Quanwen. On the long term mechanism of close relationship between cadres and masses in the new era [J]. Journal of Huaihai Institute of Techology (HUMANITIES AND SOCIAL SCIENCES), 2018, 16 (03): 1-5.

[22] $\mathrm{Hu}$ Houcui. Explore the path to accelerate the development of Internet plus government service "-- Taking Hefei city as example [J]. Journal of Harbin municipal Party school, 2018 (03): 49-53.

[23] Li Sisi. To promote the "observation Internet plus government service" construction of path $[\mathrm{J}]$. theory under the new norm, 2018 (03): 76-78.

[24] Li Yunxin, in Yeqin. "Internet plus provincial government services" promotion mechanism and policy characteristics -Based on policy text content analysis of [J]. e-government, 2018 (03): 81-91.

[25] Cheng Hao, Liu Xuran. Model and Simulation of government online public service based on cellular automata [J]. leadership science, 2018 (08): 8-11.

[26] $\mathrm{Hu}$ Yongfei, Wang Liqin. "To promote the optimization of tax service tax on $[\mathrm{J}]$. Internet plus government services, 2018 (07): 13. 